\title{
Hypoglycemic Potential of Basella alba Linn. - An In Vitro Study
}

\author{
Faiyaz Ahmed ${ }^{1 *}$ \\ ${ }^{1}$ Department of Clinical Nutrition, College of Applied Health Sciences in Ar Rass, Qassim University, Al Qassim Region 51921, Saudi Arabia.
}

\section{Abstract}

Basella alba L., often referred as Malabar spinach, is a nutritionally valuable leafy vegetable grown in Asian nations such as India and Bangladesh. Apart from being an excellent source of vitamins and minerals, the vegetable also contains significant amount of polysaccharides, which have been proven to have effective antidiabetic action in experimental diabetes. As a reason, the current study was conducted to determine the exact mechanism of hypoglycemic action of $B$. alba aerial parts. The effect of $B$. alba powder (BAP) on starch digestibility diffusion, and adsorption of glucose, was investigated in vitro. B. alba extract (BAE) was also investigated for its influence on glucose transport in yeast cells. The results showed that BAP, at both $2 \%$ and $4 \%$ concentrations, bound more glucose than wheat bran ( $2 \%)$ and also retarded glucose diffusion across the dialysis membrane. In a starch digestibility experiment, BAP at both doses (2- and 4\%) demonstrated full retardation of glucose diffusion until 120 minutes, similar to acarbose, which showed no glucose diffusion until 240 minutes. The effect of BAP at $4 \%$ was the more pronounced followed by BAP at $2 \%$ and wheat bran (2\%). Furthermore, in a dose-dependent manner, BME enhanced glucose uptake by yeast cells. However, the percentage increase in glucose uptake was inversely related to the concentration of glucose. It is concluded that $B$. alba has potential hypoglycemic effect, which is mediated by creating a physical barrier to glucose absorption in the GI tract and improving peripheral glucose utilization.

Keywords: Malabar spinach, Glucose binding, Starch digestion, Hypoglycemic

\section{INTRODUCTION}

Diabetes mellitus is a chronic metabolic disease caused by a multitude of etiology that results in high blood glucose levels. Because of the associated health complications, this illness imposes a massive economic burden on the world [1-3]. Although a variety of treatments, including oral hypoglycemic medications and insulin, are available for diabetes management, indigestible soluble polysaccharides have also been linked to improved blood glucose. Different polysaccharides isolated from mushrooms, beans, oats, pumpkin, as well as cucumber have been shown to have considerable antidiabetic properties [4-7]. A water-soluble polysaccharide comprising repeating units of rhamnose, arabinose, mannose, and galactose exhibited excellent blood glucose reduction in streptozotocin-induced diabetic rats [7]. A similar polysaccharide comprising repeating units of mannose, rhamnose, glucose, galactose, and xylose inhibited glucose absorption in vitro [8] and demonstrated strong antidiabetic efficacy in alloxan-induced diabetic rats [9]. In light of these findings, the quest for dietary sources high in soluble polysaccharides is intensifying in order to produce inexpensive, effective, and safe supplements for diabetes therapy [1].

Basella alba L., popularly known as Malabar/Indian spinach, is a neglected mucilaginous leafy vegetable grown in Asian countries like India and Bangladesh for its nutritional value
[10-14]. In addition to carbohydrates, lipids, soluble polysaccharides, and amino acids (leucine, isoleucine, lysine, arginine, threonine, and tryptophan), it is high in micronutrients such as vitamin $\mathrm{A}$, vitamin $\mathrm{C}$, vitamin $\mathrm{K}$, thiamine, riboflavin, niacin, biotin, calcium, magnesium, and iron [14-17].

Basellasaponins A, B, C, D, $\beta$-sitosterol, stigmasterol glucoside, $\beta$-vulgaroside I, syringic acid, lupeol, kaempferol, ferulic acid, rutin, betacyanin and acacetin are some of the bioactive compounds reportedly isolated from $B$. alba aerial parts [14, 18-21]. Furthermore, an acidic polysaccharide $(\mathrm{pH}$ 5.3-5.4) with arabinose, rhamnose, galactose, galacturonic acid and glucose as major repeating exhibited slow swelling capacity, strong suspending ability and high viscosity

Address for correspondence: Faiyaz Ahmed, Department of Clinical Nutrition, College of Applied Health Sciences in Ar Rass, Qassim University, Al Qassim Region 51921, Saudi Arabia. Email: f.masfoor @ qu.edu.sa

This is an open-access article distributed under the terms of the Creative Commons Attribution-Non Commercial-Share Alike 3.0 License, which allows others to remix, tweak, and build upon the work non commercially, as long as the author is credited and the new creations are licensed under the identical terms.

How to cite this article: Ahmed F. Hypoglycemic Potential of Basella alba Linn. - An In Vitro Study. Arch. Pharm. Pract. 2022;13(1):18-23. https://doi.org/10.51847/uE5RG9zRch 
resulting in considerable glucose entrapment ability and $\alpha$ glucosidase inhibitory activity in vitro [22-24]. Apart from their prospective applications in the nutraceutical industry as thickening, suspending, binding, and gelling agents, these complex polysaccharides have shown significant antidiabetic efficacy in animal studies [25-27]. However, the mechanism of its antidiabetic action has not been studied. Therefore, the current study was designed to investigate the mechanism of antidiabetic effect of $B$. alba aerial parts utilizing in vitro protocols of glucose adsorption, diffusion and glucose transport studies.

\section{Materials and Methods}

\section{Materials}

B. alba leaves with stem (aerial parts) were purchased from a local vegetable shop, later on recognized by Dr. Sharanappa and the voucher specimen (RU-002/1441-42) was retained in the laboratory for reference. Wheat bran and dried baker's yeast were purchased from Nesto Hypermarket in Ar Rass, Saudi Arabia. Dialysis membrane (12 KD, Sigma Aldrich), glucose assay kit (GOD-POD, Randox) and $\alpha$-amylase (Sigma Aldrich) were used. All of the other reagents and chemicals utilized in the analysis had the finest analytical purity.

\section{Processing of the Sample}

The sample was rinsed under running water to remove dirt before being spread out on big trays and dried in a hot air oven at $60^{\circ} \mathrm{C}$ for 24 hours. B. alba powder (BAP) was made by powdering the dried sample in a cyclonic laboratory blender until it flowed through a 60-mesh screen. BAP was stored in the refrigerator in an airtight receptacle for subsequent use.

\section{Determination BAP's Glucose Binding Ability}

BAP's ability to adsorb/bind glucose was measured using the in vitro method defined by Ahmed and Urooj [28]. In $50 \mathrm{~mL}$ centrifuge tubes, BAP (500 and $1000 \mathrm{mg}$ ) was transferred to $25 \mathrm{~mL}$ glucose dilution with raising concentrations $(5,10,20$, 50 , and $100 \mathrm{mM}$ ) and vortexed for 10 seconds. After that, the tubes were incubated at $37^{\circ} \mathrm{C}$ in an automatic shaking water incubator. The tubes were centrifuged at $4000 \times \mathrm{g}$ for 20 minutes after 6 hours of incubation to measure the glucose content in the supernatant using GOD-POD assay package. The glucose bound was measured by the formula below and expressed in milli moles $(\mathrm{mM})$. As a reference, $2 \%$ wheat bran $(500 \mathrm{mg})$ was used.

$$
\begin{aligned}
\text { Glucose Bound }= & \frac{\mathrm{G}_{0 \mathrm{~h}}-\mathrm{G}_{6 \mathrm{~h}}}{\begin{array}{l}
\text { Weight of the sample } \\
\times \text { Vol of solution }
\end{array}}
\end{aligned}
$$

Wherein, $G_{0 h}$ is the initial glucose concentration of the solution and $\mathrm{G}_{6 \mathrm{~h}}$ is the glucose concentration of the solution after 6 hours.
Impact of BAP on Retardation of Glucose

\section{Dispersion}

The effect of BAP on retardation of glucose dispersion was studied based on the method of Ahmed and Urooj [28]. Twenty-five $\mathrm{mL}$ of glucose dilution $(20 \mathrm{mM})$ and BAP (500 and $1000 \mathrm{mg}$ ) were added into dialysis bag (12 KD MW cut off) and dialyzed against $200 \mathrm{~mL}$ of distilled water taken in $250 \mathrm{~mL}$ tall form beakers. Then at the temperature of $37^{\circ} \mathrm{C}$ the beakers were placed in a shaker water bath and glucose level in the dialysate was specified at 60, 120, 180- and 240minutes by glucose oxidase peroxidase assay kit. In the lack of BAP, a control test was run. Acarbose 0.2\% (50 mg) was utilized as reference. Using the below formula the Glucose Dialysis Retardation Index (GDRI) was computed.

$$
\begin{gathered}
\text { GDRI }=100-\frac{\text { Glucose content } \text { with sample }}{\text { Glucose content of control }} \\
\times 100
\end{gathered}
$$

\section{Effect of BAP on Starch Digestibility}

The impact of BAP on in vitro starch digestibility BAP was specified based on the technique of Ahmed and Urooj [28]. Potato starch $(40 \mathrm{~g})$ was added to $900 \mathrm{~mL}$ of $0.05 \mathrm{M}$ phosphate buffer ( $\mathrm{pH}$ 6.5). The solution was heated for 30 min at $65^{\circ} \mathrm{C}$ on a magnetic stirrer with continuous stirring. The volume was made up to a terminal volume of $1000 \mathrm{~mL}$ to provide a $4 \%(\mathrm{w} / \mathrm{v})$ starch dilution. $25 \mathrm{~mL}$ of starch dilution, $0.4 \% \alpha$-amylase (100 mg) and test samples (500 and $1000 \mathrm{mg}$ ) were added into a dialysis bag and sealed dialysis bags were placed into a beaker with $200 \mathrm{~mL}$ of distilled water. The beaker was put in a shaker water bath at $37^{\circ} \mathrm{C}$ and at 60 , 120, 180 and 240 minutes the glucose value in the dialysate was specified. In the lack of BAP, a control test was run. Acarbose $0.2 \%$ (50 mg) was utilized as reference. Glucose Dialysis Retardation Index (GDRI) was computed by the following formula.

$$
\mathrm{GDRI}=100-\frac{\text { Glucose content } \text { with sample }}{\text { Glucose content of control }} \times 100
$$

\section{Effect of B. alba on Glucose Transport in Yeast Cells}

To study the effect of $B$. alba on glucose transport in yeast cells, $B$. alba water extract (BAE) was obtained by extracting B. alba powder $(10 \mathrm{~g})$ with hot distilled water $\left(150 \mathrm{~mL} ; 70^{\circ} \mathrm{C}\right)$ in a mechanical shaker. After 24 hours, the extract was filtered and freeze dried to yield $B$. alba extract (BAE) which was preserved in a deep freezer for subsequent use. Working stock containing $1 \mathrm{mg} / \mathrm{mL}$ BAE was prepared before starting the experiment. Yeast cells were prepared as previously described by Harish et al. [29]. Briefly, 10 grams of baker's yeast was added to $50 \mathrm{~mL}$ of distilled water in a stoppered centrifuge tube and vortexed for 30 seconds. The tube was centrifuged at $3000 \mathrm{~g}$ for 5 minutes. After that, the supernatant was discarded and the yeast pellet was 
redissolved in $50 \mathrm{~mL}$ of distilled water and vortexed for 30 seconds followed by centrifugation. The process was repeated until the supernatant fluid was clear. Yeast suspension $(10 \% \mathrm{w} / \mathrm{v})$ was freshly prepared with distilled water before starting the experiment. Various concentrations of BAE (1-5 mL) taken in $15 \mathrm{~mL}$ polycarbonate tubes were mixed with $1 \mathrm{~mL}$ of glucose dilution $(5-25 \mathrm{mM})$. The volume was made up to $6 \mathrm{~mL}$ with distilled water and incubated together at $37^{\circ} \mathrm{C}$. After $10 \mathrm{~min}, 100 \mu \mathrm{L}$ of yeast suspension was added, vortexed and incubated further for $60 \mathrm{~min}$ at $37^{\circ} \mathrm{C}$. The tubes were then centrifuged at $2500 \times \mathrm{g}$ for $5 \mathrm{~min}$ and the glucose content in the supernatant was determined by GOD-POD assay. For calculating the percentage of enhancement in glucose uptake by yeast cells, the following formula was used:

Increase in glucose uptake (\%)

$$
=\frac{A b s(C)-A b s(S)}{A b s(C)} \times 100
$$

In which, $A b s(C)$ is the absorption of the control reaction that contained all reagents except the test sample and $A b s(S)$ is the absorption of the test sample.

\section{Statistical Analysis}

All in vitro experiments were performed in three replicates ( $\mathrm{n}$ =6). Using SPSS 20.0 software, data were subjected to Analysis of Variance (ANOVA) followed by post-hoc test (Tukey's multiple comparisons) to determine significant differences between groups at $95 \%$ confidence level. All of the graphs were plotted by OriginPro software (OriginLab Corporation, MA, USA). Double axis layered graphs were plotted in case of glucose diffusion and starch digestibility experiments having line chart corresponding to GDRI values in $\mathrm{Y} 2$ axis.

\section{REsults AND Discussion}

\section{Glucose Binding Ability of BAP}

The glucose binding ability of BAP and wheat bran are presented in Figure 1. Glucose-binding potential of both BAP and wheat bran were found to be straightly proportionate to glucose concentration and highest amount of glucose was adsorbed at 100 milli moles concentration. Similar observations were reported with respect to oats, barley and psyllium husk, wherein glucose adsorption capacity of these fiber sources increased with increasing molar concentration of glucose [30]. BAP (4\%) was able to bind significantly more $(\mathrm{p}<0.05)$ amount of glucose than BAP at $2 \%$, however glucose adsorption capacity of BAP at both $2 \%$ and $4 \%$ level was significantly more $(\mathrm{p}<0.05)$ than that of wheat bran at all glucose concentrations. This could be because wheat bran primarily contains insoluble fibers whose water holding capacity is lower than that of soluble gel forming polysaccharides that are abundantly present in $B$. alba aerial parts $[23,30]$. It is noteworthy that $B$. alba polysaccharides are reported to form a stable gel which resists phase separation, precipitation, change in color, odor or $\mathrm{pH}$ during heating/cooling operations [23]. Reports have indicated that dietary fibers vary in their ability to control hyperglycemia depending on their source, composition and the type of dietary formulation they are used in $[31,32]$.

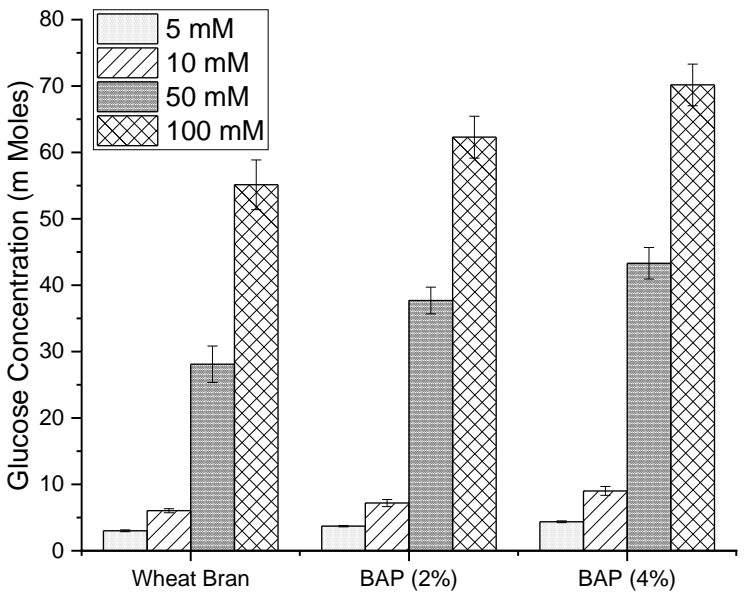

Figure 1. Glucose Binding Ability of Basella alba Powder

Soluble and mucilaginous polysaccharides including gums and pectin are known to increase viscosity of intestinal contents and bind glucose, cholesterol and triglycerides in GI tract ultimately resulting in the attenuation of post-prandial glucose response and serum lipid levels [33]. The ability of BAP to adsorb substantial amounts of glucose in a dose dependent manner therefore, create an opportunity to use $B$. alba vegetable as a functional ingredient in food products for effectively reducing the rate of glucose absorption from the GI tract and consequently decreasing post-meal plasma glucose rise in diabetics.

\section{Effect of BAP on Retardation of Glucose Diffusion}

Studying the dynamics of glucose diffusion across dialysis membrane is a suitable in vitro technique helpful to anticipate the ability of dietary components to delay glucose absorption from the gastrointestinal lumen into circulation [33]. In this research, the amount of glucose dispersion through dialysis membrane of $12 \mathrm{KD}$ cutoff was controlled once in 60 minutes for 240 minutes using BAP at two levels $(2 \% \& 4 \%)$ and compared with wheat bran $(2 \%)$ as a reference fiber source. The findings of the experiments are presented in Figure 2. It was found that, BAP at 2- and $4 \%$ resulted in a substantial inhibition of glucose diffusion into external solution through dialysis membrane in comparison to control experiment without the presence of any sample. It was also observed that though, BAP at $4 \%$ indicated significantly higher $(\mathrm{p}<0.05)$ prohibition of glucose dispersion in comparison to BAP at $2 \%$ as indicated by Glucose Dialysis Retardation Index (GDRI) values, the glucose dispersion inhibitory effect of BAP at both 2 - and $4 \%$ was higher $(\mathrm{p}<0.05)$ than that of wheat bran at all time intervals.

The dialysis procedures are intended to replicate activities that occur in the gastrointestinal tract. In this procedure, movement is aided by the convective motion of the intestinal 
contraction in vivo by shaking, which more accurately simulates the biological system than an unstirred system. This study was conducted to determine the effect of BAP in inhibiting glucose movement and to use the findings to predict how these polysaccharides would lower postprandial serum glucose levels.

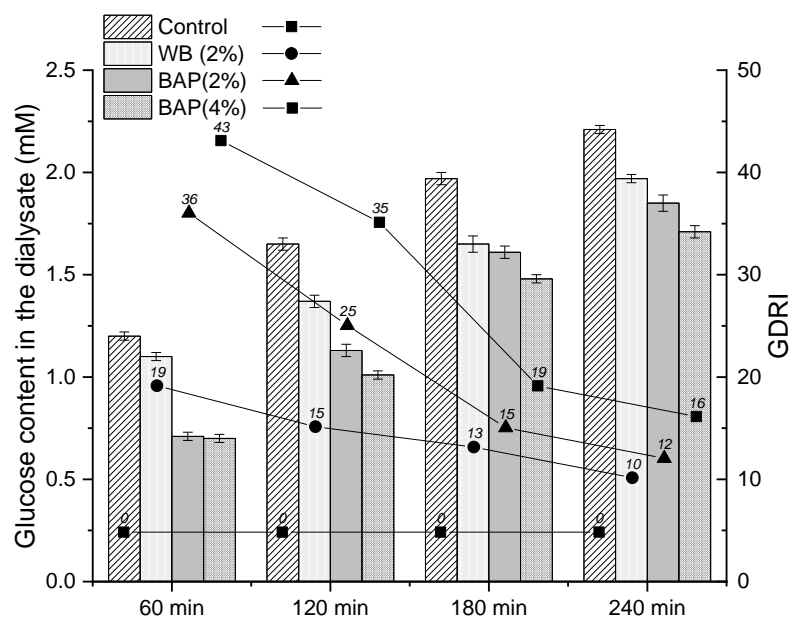

Figure 2. Effect of BAP on Retardation of Glucose Diffusion

The GDRI is an in vitro index that predicts the influence of fiber on glucose absorbance from GI tract [34]. The current study showed that GDRI values for all samples decreased from 60 to 240 minutes, which is consistent with an earlier study that found that the maximum GDRI values were found at 30 minutes and then decreased by 180 minutes for soluble fiber dense foods like oats and psyllium [30]. The occurrence of viscous polysaccharides in B. alba leaves [23] are clearly responsible for the observed pattern of declining GDRI values over time, as fiber molecules act as physical barrier to the movement of glucose by entrapping them within the fiber matrix [33-35].

\section{Effect of BAP on in vitro Starch Digestibility}

In a typical Asian diet, starch is the major dietary component providing glucose as a source of energy consequently resulting in higher blood glucose levels in circulation post consumption of starch-rich meal. Thus, use of dietary components which delay the digestion of dietary carbohydrates and absorption of glucose from GI tract is a viable therapeutic strategy to manage postprandial hyperglycemia in diabetics [36]. In the current study, the ability of BAP to delay starch digestion and glucose absorption was studied using starch-amylase-BAP system in vitro. The findings are shown in Figure 3. In comparison to control, the dispersion amount of glucose in the systems including samples (BAP 2\% and 4\%) was substantially $(p<0.05)$ lower at each period of time. For acarbose, which results in completing the inhibition of $\alpha$-amylase, no glucose diffusion was observed at all time intervals, while in a system containing BAP (2\% and 4\%) no glucose diffusion was observed at 120 minutes.

GDRI is a measure of the ability of the sample to inhibit glucose diffusion through dialysis membrane. Acarbose exhibited the highest GDRI of 100 at all time and prevented diffusion of glucose completely as it is known inhibiter of $\alpha$ amylase thereby preventing digestion of starch $[37,38]$. On the other hand, both BAP $2 \%$ and 4\% showed a GDRI of 100 till $120 \mathrm{~min}$ and subsequently allowed diffusion of glucose at 180 min and onwards, while wheat bran showed complete inhibition of glucose diffusion only at $60 \mathrm{~min}$.

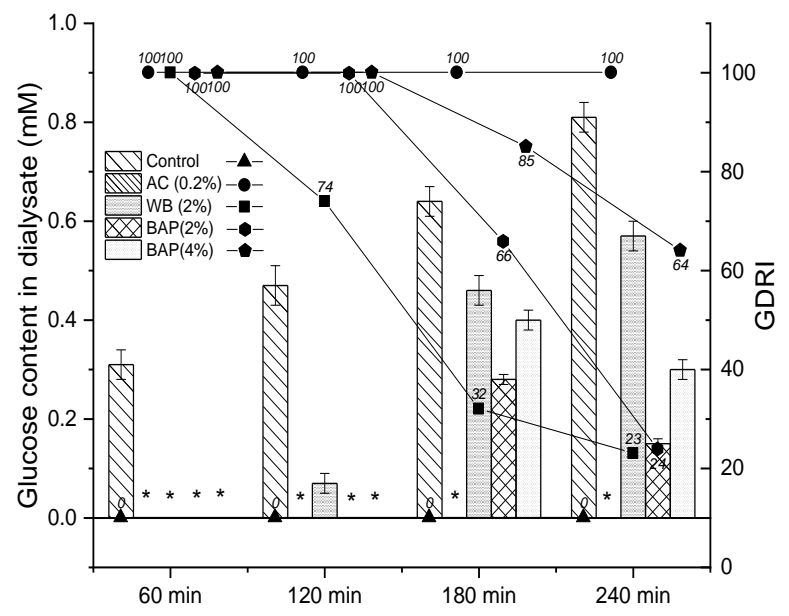

Figure 3. Effect of BAP on Starch Digestibility

The presence of water-soluble gel forming polysaccharides composed of galactose, arabinose, glucose, galacturonic acid, and rhamnose repeating units in the ratio of 41:24:16:13:5 and starch type glucan composed of L-arabinose, Dgalactose, uronic acid, and L-rhamnose can be clearly attributed to $B$. alba's glucose diffusion inhibitory effect [23]. Although B. alba leaves contain some flavonoids and phenolics, including kaempferol, a potent inhibitor of $\alpha$ amylase, the observed activity cannot be attributed to them because various extracts and juice prepared from the aerial parts of $B$. alba have shown no $\alpha$-amylase inhibitory activity in vitro $[39,40]$. As a consequence, it is reasonable to believe that the polysaccharides molecules interfere with glucose movement by physically adsorbing or entrapping glucose molecules within the fiber matrix [30], with the effect being directly proportional to the level of viscosity given by the gelforming polysaccharides of $B$. alba. These findings are consistent with a previous study in which mucilage extracted from $B$. alba demonstrated significant glucose entrapment ability in vitro [24]. These results are also consistent with an earlier study in which juice produced from B. abla leaves decreased both starch and glucose-induced post-prandial glycemic load in normoglycemic rats [40].

Effect of BAE on Glucose Transport in Yeast Cells 
The pathways of glucose transport through the yeast cell membrane have been explored as an in vitro approach for evaluating the antidiabetic impact of different dietary components. A late study about transportation of nonmetabolizable sugars and specific metabolizable glycosides shows that, while stereospecific membrane carriers are involved in sugar transport through the yeast cell membrane, it is mostly a facilitated diffusion process influenced by concentration gradients [41].

The amount of glucose transport through the cell membrane in yeast cells has been shown in Figure 4. The content of glucose left in the medium after a determined time period acts as a measure of yeast cell glucose uptake. After being added to the medium, BME enhanced yeast cells' glucose uptake in a dose-dependent way. In all five glucose concentrations, the content of glucose absorption into yeast cells was linear. Nevertheless, the percentage of enhancement in yeast cells' glucose uptake was shown to be oppositely related to the glucose concentration and reduced as the concentration of the glucose increased. This could be due to the fact that glucose transport in yeast cells is quite complicated, and that glucose is carried in yeast by a facilitated dispersion mechanism wherein, facilitated carriers move solutes along a concentration gradient in a specified way. This implies that effective transport requires the removal of intracellular glucose [41, 42]. These findings are consistent with previous research, which found that various plant extracts elicited a dose-dependent enhancement in yeast cells' glucose uptake that was oppositely proportionate to the molar concentration of the glucose [29, 43, 44].

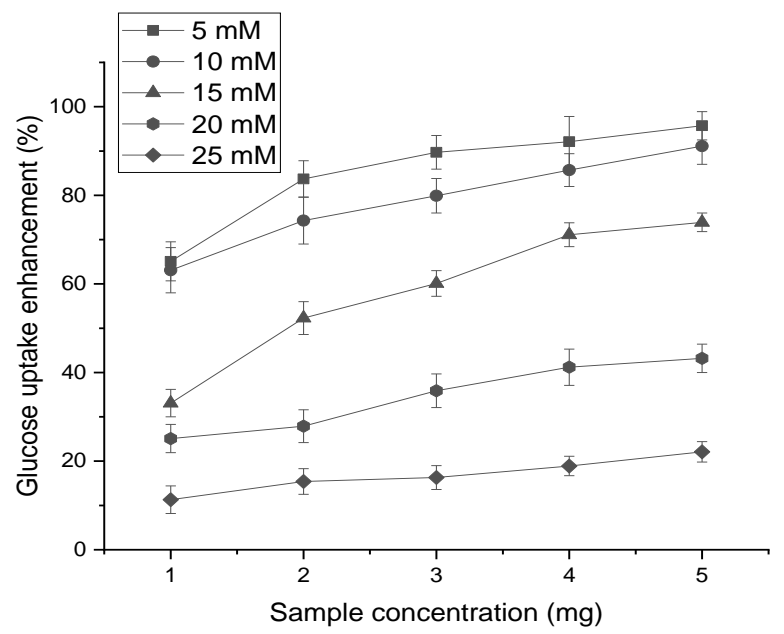

Figure 4. Impact of BAE on Glucose Transport in Yeast Cells

\section{Conclusion}

Based on the findings of this study, it is concluded that $B$. alba aerial parts rich in soluble polysaccharides have a potential hypoglycemic effect in vitro. Furthermore, the hypoglycemic effect is mediated by creating a physical barrier to glucose absorption in the GI tract, which aids in the extended release of glucose into the bloodstream and curtails rapid blood glucose surges.

ACKNOWLEDGMENTS: The author wishes to thank Dr. Bader I. Alharbi, Associate Professor, Department of English and Translation, Qassim University, for his assistance in preparing this article.

CONFLICT OF INTEREST: None

FINANCIAL SUPPORT: None

ETHICS STATEMENT: None

\section{REFERENCES}

1. Ganesan K, Xu B. Anti-diabetic effects and mechanisms of dietary polysaccharides. Molecules. 2019;24(14):2556.

2. Ahmed IA, Alosaimi ME, Alkhathami SM, Alkhurayb NT, Alrasheed MS, Alanazi ZM, et al. Knowledge, attitude, and practices towards diabetes mellitus among non-diabetes community members of Riyadh, Kingdom of Saudi Arabia. Int J Pharm Res Allied Sci. 2020;9(1):4151 .

3. Alqudsi KK, Abdelaziz SA, Al-Agha AE. Association between Vitamin D Status and Type 1 Diabetes Mellitus in Saudi Adolescents. Int J Pharm Res Allied Sci. 2019;8(3):204-11.

4. Wang D, Li C, Fan W, Yi T, Wei A, Ma Y. Hypoglycemic and hypolipidemic effects of a polysaccharide from Fructus Corni in streptozotocin-induced diabetic rats. Int $\mathrm{J}$ Biol Macromol. 2019;133:420-7.

5. Liu C, Song J, Teng M, Zheng X, Li X, Tian Y, et al. Antidiabetic and antinephritic activities of aqueous extract of Cordyceps militaris fruit body in diet-streptozotocin-induced diabetic Sprague Dawley rats. Oxid Med Cell Longev. 2016;2016:9685257.

6. Chen Y, Liu Y, Sarker MMR, Yan X, Yang C, Zhao L, et al. Structural characterization and antidiabetic potential of a novel heteropolysaccharide from Grifola frondosa via IRS1/PI3K-JNK signaling pathways. Carbohydr Polym. 2018;198:452-61.

7. Zhao T, Mao GH, Zhang M, Li F, Zou Y, Zhou Y, et al. Anti-diabetic effects of polysaccharides from ethanol-insoluble residue of Schisandra chinensis (Turcz.) Baill on alloxan-induced diabetic mice. Chem Res Chin Univ. 2013;29:99-102.

8. Tang HL, Chen C, Wang SK, Sun GJ. Biochemical analysis and hypoglycemic activity of a polysaccharide isolated from the fruit of Lycium barbarum L. Int J Biol Macromol. 2015;77:235-42.

9. Xu W, Zhou Q, Yin JJ, Yao Y, Zhang JL. Anti-diabetic effects of polysaccharides from Talinum triangulare in streptozotocin (STZ)induced type 2 diabetic male mice. Int J Biol Macromol. 2015;72:5759 .

10. Olgorite A. Genetic relationship between Basella alba and Basella rubra. WARA Newsletter; 2006. pp. 9-10.

11. Roy SK, Gangopadhyay G, Mukherjee KK. Is stem twining form of Basella alba L. a naturally occurring variant? Curr Sci. 2010;98(10):1370-5.

12. Varalakshmi B, Devaraju. Genetic variability in Indian spinach (Basella alba L.). J Hortic Sci. 2010;5(1):21-4.

13. Wambugu PW, Muthamia ZK. The state of Plant genetic resources for food and agriculture in Kenya. Submitted to FAO Commission on Plant Genetic Resources for Food and Agriculture. 2009.

14. Khare CP. Indian Medicinal Plants: An illustrated dictionary. SpringerVerlag Berlin/ Heidenberg; 2007. p. 83.

15. Duke JA, Ayensu ES. Medicinal plants of China. Reference publications, Inc. 1985. ISBN 0-917256-20-4.

16. Palada MC, Crossman SMA. Planting density affects growth and yield of bush okra. Proceedings of the 34th Annual Meeting. Caribb Food Crops Soc. 1998;34:52-7.

17. Grubben GJH, Denton OA. Plant Resources of Tropical African vegetables. Wageningen; Backhuys Leiden (CTA). Wageningen: PROTA Foundation. 2004.

18. Iwamoto M, Okabe H, Yamauchi T. Studies on the constituents of Momordica cochinchinensis SPERNG II. Isolation and characterization of the root saponins, momordins I, II and III. Chem Pharm Bull. 1985;33(1):1-7.

19. Murakami T, Matsuda H, Inadzuki M, Hirano K, Yoshikawa M. Medicinal foodstuffs. XVI. Sugar Beet (3): absolute stereo structures 
of betavulgarosides II and IV, Hypoglycemic saponins having a unique substituent from the roots of Beta vulgaris L. Chem Pharm Bull. 1999;47(12):1717-24.

20. Paul SB, Singha S. Isolation and identification of physiologically important sterols and sterol glucoside from Basella rubra L. Assam University Journal of Science and Technology: Biol Environ Sci. 2010;5(1):120-2

21. Murakami T, Hirano K, Yoshikawa M. Medicinal Foodstuffs. XXIII. 1) Structures of New Oleanane-Type Triterpene Oligoglycosides, Basellasaponins A, B, C, and D, from the Fresh Aerial Parts of Basella rubra L. Chem Pharm Bull. 2001;49(6):776-9.

22. Pareek V, Singh M, Bhat ZA, Singh P, Kumar D, Sheela S. Studies on mucilage of Basella alba Linn. J Pharm Res. 2010;3(8):1892-4.

23. Chatchawal C, Nualkaew N, Preeprame S, Porasuphatana S, Priprame A. Physical and biological properties of mucilage from Basella alba L. stem and its gel formulation. Isan J Pharm Sci. 2010;6(3):104-12.

24. Palanuvej C, Hokputsa, S, Tunsaringkarn T, Ruangrungsi N. In vitro glucose entrapment and alpha- glucosidase inhibition of mucilaginous substances from selected Thai medicinal plants. Sci Pharm. 2009;77(4):837-50.

25. Jani GK, Shah DP, Jain VC, Patel MJ, Vithalani DA. Evaluating mucilage from Aloe barbadensis Miller as a pharmaceutical excipient for sustained release matrix tablets. Pharm Technol. 2007;31(11):90-8.

26. Nirmala A, Saroja S, Gayathri Devi G. Antidiabetic activity of Basella rubra and its relationship: with the antioxidant property. Br Biotechnol J. 2011;1(1):1-9.

27. Nirmala A, Saroja S, Vasanthi HR, Lalitha G. Hypoglycemic effect of Basella rubra in streptozotocin induced diabetic albino rats. J Pharmacogn Phytother. 2009;1(2):25-30.

28. Ahmed F, Urooj A. In vitro studies on the hypoglycemic potential of Ficus racemosa steam bark. J Sci Food Agric. 2010;90(3):397-401.

29. Harish M, Ahmed F, Urooj U. In vitro hypoglycemic effects of Butea monosperma Lam. leaves and bark. J Food Sci Technol. 2014;51(2):308-14.

30. Ahmed F, Sairam S, Urooj A. In vitro hypoglycemic effects of selected dietary fiber sources. J Food Sci Technol. 2011;48(3):285-9.

31. Chau CF, Huang YL. Characterization of passion fruit seed fibres-A potential fibre source. Food Chem. 2004;85(2):189-94.

32. Yeh HY, Su NW, Lee MH. Chemical compositions and physicochemical properties of the fiber-rich materials prepared from Shoyu mash residue. J Agricu Food Chem. 2005;53(11):4361-6.
33. Gupta P, Premavalli KS. In-vitro studies on functional properties of selected natural dietary fibers. Int J Food Prop. 2011;14(2):397-410.

34. Lopez G, Ros G, Rincon F, Periago MJ, Martinez MC, Ortuno J. Relationship between physical and hydration properties of soluble and insoluble fiber of artichoke. J Agricu Food Chem. 1996;44(9):2773-8.

35. Jenkins DJA, Wolever TMS, Leeds AR, Gassul MA, Haisman P, Dilawari J, et al. Dietary fibers, fiber analogues and glucose tolerance: importance of viscosity. Br Med J. 1978;1(6124):1392-4.

36. Butterworth PJ, Warren JF, Ellis PR. Human $\alpha$-amylase and starch digestion: An interesting marriage. Starch/Strake. 2011;63(7):395-405.

37. Bischoff H. Pharmacology of alpha-glucosidase inhibition. Eur J Clin Invest. 1994;24(S3):3-10.

38. Li K, Yao F, Xue Q, Fan H, Yang L, Li X, et al. Inhibitory effects against $\alpha$-glucosidase and $\alpha$-amylase of the flavonoids-rich extract from Scutellaria baicalensis shoots and interpretation of structureactivity relationship of its eight flavonoids by a refined assign-score method. Chem Cent J. 2018;12(1):82.

39. Thavamani S, Subburaj V. In vitro studies on Basella rubra different extracts as inhibitors of key enzymes linked to diabetes mellitus. Pharmacogn J. 2016;9(1):107-11.

40. Tiwari AK, Jyothi AL, Tejeswini VB, Madhusudana K, Kumar DA, Zehra A, et al. Mitigation of starch and glucose-induced postprandial glycemic excursion in rats by antioxidant-rich green-leafy vegetables' juice. Pharmacogn Mag. 2013;9(1): S66-S73.

41. Illiano G, Cuatrecasas P. Glucose transport in fat cell membranes. J Biol Chem. 1971;246(8):2472-9.

42. Teysink B, Jasper A, Diderich HV, Westerhoff DKV, Walsh MC Intracellular glucose concentration in derepressed yeast cells consuming glucose is high enough to reduce the glucose transport rate by 50\%. J Bacteriol. 1998;180(3):556-62.

43. Bhutkar MA, Bhinge SD, Randive DS, Wadkar GH. Hypoglycemic effects of Berberis aristata and Tamarindus indica extracts in vitro. Bull Fac Pharm, Cairo Univ. 2017;55(1):91-4.

44. Shettar AK, Sateesh MK, Kaliwal BB, Vedamurthya AB. In vitro antidiabetic activities and GC-MS phytochemical analysis of Ximenia americana extracts. S Afr J Bot. 2017;111:202-11. 